\title{
The application of laparoscopy in abdominal trauma at Al-Jumhoori Teaching Hospital in Mosul
}

\author{
Muzahim K. Al-Khyatt*, Saad M. Attash**, Mohammed S. Ali ***, \\ Khalid A. Al-Dabbagh***, Muthanna Asaad*** \\ * Professor of General and Laparoscopic Surgery, Department of Surgery, College of Medicine, University of \\ Mosul;** Registrar in General Surgery, Department of Surgery, Nineveh Medical College, University of Mosul; \\ *** Consultant Surgeon, Al-Jumhoori Teaching Hospital, Mosul.
}

(Ann. Coll. Med. Mosul 2012; 38 (2): 1-4).

Received: $2^{\text {nd }}$ Jan. 2012; Accepted: $20^{\text {th }}$ Jun. 2012.

\begin{abstract}
Objective: To evaluate laparoscopy as a diagnostic and therapeutic method in selected cases in abdominal trauma, and its value in avoiding unnecessary laparotomies at Al-Jumhoori Teaching Hospital in Mosul, Iraq. Patients and methods: From October 2009 to October 2011, sixty hemodynamically stable patients who were admitted with abdominal trauma (48 blunt, and 12 penetrating injuries), were submitted to diagnostic laparoscopy (DL) in the operating theatre of the Emergency Department of Al-Jumhoori Teaching Hospital in Mosul. Data collected and analyzed.

Results: Negative and non therapeutic laparotomies were avoided in 38 patients (63.3\%), and laparoscopic intervention was done in 4 patients (17.4\%). The mean hospital stay of the (DL) negative patients was 2.1 days, and for the (DL) positive patients with laparoscopic intervention was 2.4 days, while of the patients with therapeutic laparotomy was 5.7 days. All the patients were discharged with no reported complication and no deaths were reported.

Conclusion: Laparoscopy can be performed safely and effectively in hemodynamically stable patients with abdominal trauma. The most important advantages are reduction of the negative and non therapeutic laparotomy rate and shortening of hospitalization.
\end{abstract}

Keywords: Blunt abdominal trauma, penetrating abdominal trauma, diagnostic laparoscopy.

الهُف: لمعرفة مدى فعالية منظار البطن كأداة تشخيصية في حالات إصابات البطن و إمكانية استخدامه في التعامل مع بعض هذه

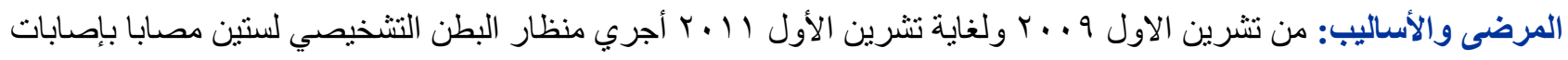

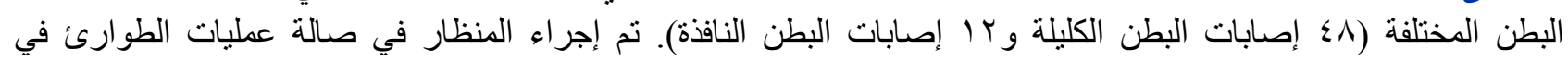

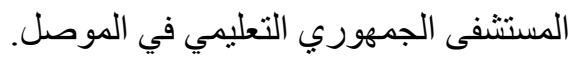

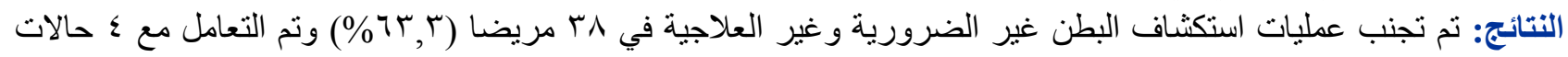

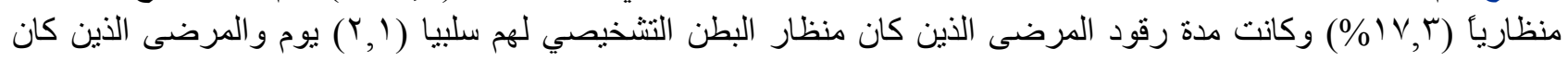

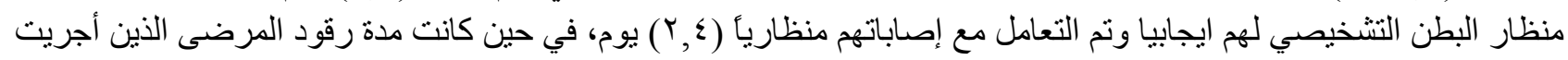

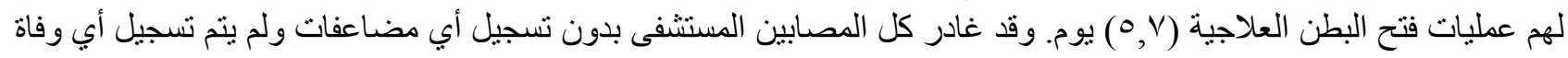
بين المصابين. الخلاصة: يمكن إجر اء منظار البطن التشخيصي للمرضى المصابين بإصابات البطن بصورة أمينة وفعالة. أهم الفو ائد من استخدام

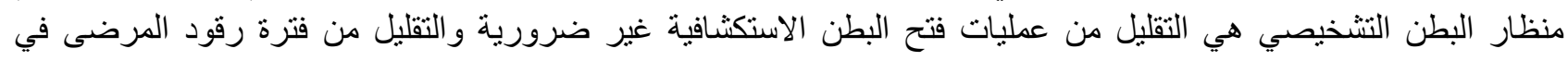




\section{الكلمات الدالة: إصابات البطن الكليلة، إصابات البطن النافذة، منظار البطن التشخيصي.}

$\mathrm{T}$ rauma is the leading cause of death between the ages of 1 and 44 years. In all age groups, it is surpassed only by cancer and atherosclerosis in mortality. The evaluation and treatment of abdominal injuries are critical components in the management of severely injured trauma patients ${ }^{(1)}$.

Abdominal trauma can be either blunt or penetrating, the most common cause of blunt abdominal trauma in metropolitan trauma centers is the motor vehicle accident (MVA), responsible for $45 \%$ to $50 \%$ of BATs. Assaults, falls, automobile-pedestrian accidents and work-related injuries are also common. Abdominal injuries in blunt trauma result from compression, crushing, shearing, or deceleration mechanisms. Fortunately, the incidence of BAT requiring laparotomy is only $6 \%$. The most frequently injured organs are the spleen (40\% to $55 \%$ ), the liver (35\% to $45 \%$ ), and the retroperitoneum (15\%). Gunshot wounds are the most common cause (64\%) of penetrating abdominal trauma, followed by stab wounds (31\%) and shotgun wounds (5\%). Injury patterns differ depending on the weapon ${ }^{(2)}$.

Minimally invasive surgical techniques have become increasingly utilized in all areas of surgery. Current use of laparoscopy in the evaluation and management of trauma patients has been a natural extension of this trend. Several studies have analyzed various aspects of its application to the trauma patient ${ }^{(3)}$.

Laparoscopy was first used for a trauma patient in 1986 by Lamy, who observed two cases of splenic injury. Since then, Gazzaniga et al. noted that laparoscopy is useful for determining the need for laparotomy ${ }^{(4)}$. In 1991, Berci et al. reported that he had reduced the number of non-therapeutic laparotomies performed for hemoperitoneum by $25 \%$ through the use of laparoscopy in 150 patients with blunt abdominal trauma ${ }^{(5)}$. Sosa et al found laparoscopy to be $100 \%$ accurate in identifying peritoneal stab wounds ${ }^{(6)}$. Livingston et al and Brandt et al considered laparoscopy of potential benefit for abdominal wounds of unclear trajectory, noting that only $30 \%$ to $40 \%$ of abdominal stab wounds require surgery ${ }^{(3,7)}$.

The main indication for (DL) in abdominal trauma is suspected but unproven intra-abdominal injury after blunt or penetrating trauma, whilst the main contraindications are: Hemodynamic instability (defined by most studies as systolic pressure $<90$ $\mathrm{mm} \mathrm{Hg}$ ), known or obvious intra-abdominal injury, posterior penetrating trauma with high likelihood of bowel injury, and limited laparoscopic expertise. ${ }^{(8,9)}$

The most important risk of (DL) for abdominal injury is missed injuries, mainly intestinal, while some authors found that laparoscopy is inadequate for detecting intestinal injuries other centers, including ours, did not report any missed injuries ${ }^{(10,11)}$.

The aim of this study was to evaluate laparoscopy as a diagnostic and therapeutic method in selected cases and its ability to avoid unnecessary laparotomies.

\section{MATERIAL AND METHODS}

From October 2009 to October 2011, 60 consecutive patients with abdominal trauma underwent diagnostic laparoscopy in the operating theatre of the Emergency Department of AlJumhoori Teaching Hospital in Mosul. The total no. of abdominal trauma cases in the same period was 432, with 316 laparotomies for trauma performed.

The mean age of the patients was 25.57 years ranging from 2 to 56 years, 51 males and 9 females. Forty-eight of the patients had blunt abdominal trauma, of them 38 patients were victims of motor vehicle accidents and 10 were other types of blunt trauma to the abdomen including 4 cases of falling from height and 6 cases of direct trauma to the abdomen during quarrels, 12 patients had penetrating trauma, 8 of them were stab injuries, 2 gunshot injuries, and 2 shrapnel injuries.

Criteria for inclusion in the study were: suspected but unproven intra abdominal injury in patients who were upon arrival, or after initial resuscitation, hemodynamically stable. They presented normal Glasgow coma scale and limited associated injuries, and surgical team and technical conditions were adequate. All had investigations (like FAST examination or CT scan) with equivocal results.

Criteria for excluding patients from the study were: hemodynamic instability despite resuscitation, known or obvious intra-abdominal 
injury, and posterior penetrating trauma with high likelihood of bowel and retro peritoneal injuries.

Data collection was done directly from the patient, history and clinical examination, investigations, findings and interventions during $(\mathrm{DL})$, the presence of associated injuries and the need for conversion to open surgery were recorded on a performa together with the follow up of the patients including the need for reexploration.

All the procedures were done under general anesthesia. Pneumo-peritoneum was created with carbon dioxide. The video-optic port was set infra umbilically with a $10 \mathrm{~mm}$ trocar. The choice of location for the second $5 \mathrm{~mm}$ port depended upon the findings in the initial laparoscopic view. Besides these two routine ports, accessory ports were set if indicated.

All the patients were followed for a period ranging from 10-15 days, both during their hospitalization and in their follow up visit after discharge. Careful monitoring of hospitalized patients was performed during frequent daily visits, and charts (for the vital signs, abdominal pain, bowel sounds and motion, urine output and outputs of drains).

\section{RESULTS}

The total number of patients who needed (DL) was 60 . The (DL) was negative in 37 of the patients $(61.7 \%)$, including 32 patients with blunt trauma $(86.5 \%)$ and 5 patients with penetrating trauma $(13.5 \%)$, and was positive in 23 of the patients (38.3\%) of the total (60), including 16 patients with blunt trauma $(69.5 \%)$ and 7 patients with penetrating $(30.5 \%)$.

Laparoscopy negative patients were kept under monitoring for a period of 1-3 days, discharged without morbidity, and followed as out patients for 2 weeks without any reported complications.

Of the laparoscopy positive patients, 18 patients (12 blunt, 2 stab wounds, 2 gun shot and 2 shrapnel injuries) needed immediate exploration because of significant injury that is difficult to be dealt with laparoscopically.

Four patients with blunt abdominal trauma were dealt with laparoscopically, using cauterization of a simple liver bleeding in two cases, omental and mesenteric bleeding in the third and forth case respectively. The other patient with a penetrating stab wound injury had a simple hematoma in the body of the stomach that didn't need any intervention (Table 1).

The mean hospital stay of the (DL) negative patients was 1.7 days, and for the (DL) positive patients with laparoscopic intervention was 2.5 days, while of the patients with therapeutic laparotomy was 6.6 days (Figure 1).

All the patients were discharged with no reported complication and no deaths were reported in our study.

Table 1. Management of 23 patients with positive (DL).

\begin{tabular}{|l|c|c|}
\hline $\begin{array}{c}\text { Intervention done after } \\
\text { a positive DL }\end{array}$ & $\begin{array}{c}\text { No. of } \\
\text { patients }\end{array}$ & Percentage \\
\hline Therapeutic laparotomy & 18 & 78 \\
\hline Laparoscopic intervention & 4 & 17.4 \\
\hline None & 1 & 4.4 \\
\hline
\end{tabular}

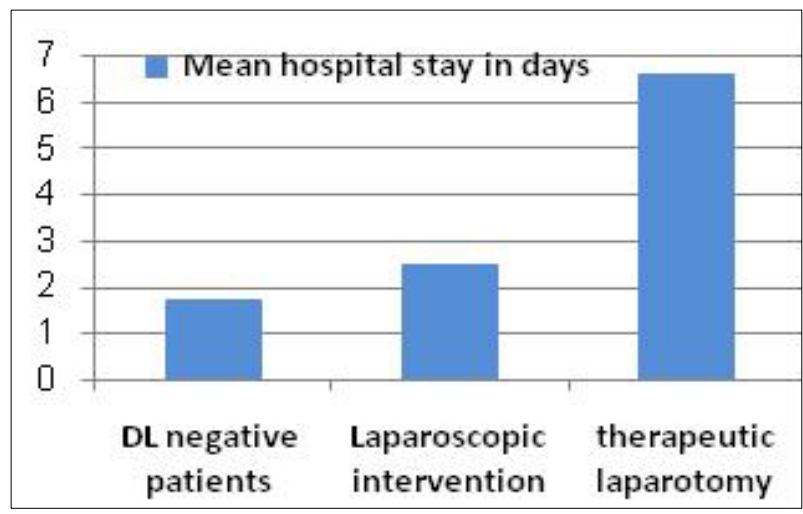

Figure 1. Mean hospital stay.

\section{DISCUSSION}

In the evaluation and management of abdominal injury, current diagnostic methods have a defined sensitivity, specificity, and accuracy, but none of these represents a gold standard. ${ }^{(12)}$ Thus abdominal exploration by laparotomy should not be discarded as a worthy diagnostic and therapeutic procedure for patients with equivocal and unreliable findings. It is associated with complication rates as high as $40 \%$ including a 10 $40 \%$ negative laparotomy rate, a $20 \%$ morbidity rate, a $0 \%$ to $5 \%$ mortality rate, and a $3 \%$ longterm risk of bowel obstruction secondary to adhesions. ${ }^{(12)}$

Our study demonstrated that unnecessary laparotomy was avoided in $63.3 \%$ of the patients. Out of 23 patients with positive (DL), therapeutic laparoscopy was performed in 4 patients (17.4\%), 
including hemostasis of liver, mesentery and omentum. In 18 patients (78.2\%) conversion was necessary because of inadequate examination, injuries that cannot be repaired by laparoscopy, surgeon's lack of experience and clinical instability. All the patients were discharged without morbidity and mortality, and none of the patients reported for complications.

Zantut and col. evaluated the role of diagnostic and therapeutic laparoscopy in a multicenter study of 510 patients, Laparotomy was avoided in 277 patients $(54.3 \%)$, therapeutic procedures were performed in another 26 patients (5.1\%), and therapeutic laparotomy was performed in 155 patients out of the 203 patients submitted to laparotomy and 52 patients (25\%) were submitted to unnecessary laparotomy ${ }^{(13)}$. In contrast, Chol and Lim performed therapeutic procedure associated with laparoscopy in $100 \%$ of the 78 patients of the series ${ }^{(14)}$.

In our study, the mean hospital stay of the (DL) negative patients was 1.7 days, and for the (DL) positive patients with laparoscopic intervention was 2.5 days, while of the patients with therapeutic laparotomy was 6.6 days. Simon stated that one of the greatest advantages of this method was the shorter hospital stay compared to patients submitted to laparotomy ranging from $2.2 \pm 1.1$ to $4.0 \pm 1.7$ days, respectively. Beside this, unnecessary laparotomy was avoided in 25 patients, out of the 45 patients submitted to laparoscopy. ${ }^{(15)}$

It should be emphasized that the use of laparoscopy in patients with trauma is reserved for hemodynamically stable patients and that laparoscopy have limitations in dorsal stab injuries to the hollow organs. The opinion in the early 1990s, supported by published data, that there was a higher incidence of complications with laparoscopy is now outdated, due to increasing experience and technical improvements ${ }^{(16)}$.

\section{CONCLUSIONS}

Laparoscopy can be performed safely and effectively in stable patients with abdominal trauma. It is considered as an important tool in the evaluation of penetrating and blunt abdominal trauma. The most important advantages are the reduction of the negative and non-therapeutic laparotomy rate and shortening of hospitalization.

\section{REFERENCES}

1. American College of Surgeons. ATLS program for doctors Chicago: First Impressions.1997.p.193-211.

2. Fabian TC, Croce MA. Abdominal trauma, including indications for celiotomy. MattoxKL, FelicianoDV, MooreEE, editors. Trauma New York: McGraw-Hill; 2000. p.1583-602.

3. Livingston DH, Tortella BJ, Blackwood J, Machiedo GW, Rush BF. The role of laparoscopy in abdominal trauma. J Trauma1992; 33: 471-475.

4. Gazzaniga $A B$, Slanton WW, Bartlett $R H$, et al. Laparoscopy in the diagnosis of blunt and penetrating injuries to abdomen. Am J Surg .1996; 131: 315-318.

5. Berci G, Sackier JM, Paz-Parlow $M$, et al. Emergency laparoscopy.Am J Surg. 1991; 161: 332-335.

6. Sosa JL, Arrillaga A, Puente I, et al. Laparoscopy in 121 consecutive patients with abdominal gunshot wounds. J Trauma .1995; 39: 501-506.

7. Brandt CP, Piebe PP, Jacobs DG. Potential of laparoscopy to reduce non therapeutic trauma laparotomies. Ann Surg .1994 ;60: 416-420.

8. Rossi P, Mullins D, Thai E, et al. Role of laparoscopy in the evaluation of abdominal trauma. Am J Surg. 1993; 166: 707-711.

9. Ivatury RR, Simon RJ, Stahl WM, et al. A critical evaluation of laparoscopy in penetrating abdominal trauma. J Trauma. 1993;34:822-8.

10. Soper NJ, Brunt LM, Fleshman J. Laparoscopic small bowel resection and anastomosis. Surg Laparosc Endosc. 1993; 3: 6-12.

11. Pietrafitta JJ, Schultz KS, Graber JN, et al. An experimental technique of laparoscopic bowel resection and reanastomosis. Surg Laparosc Endosc .1992; 2: 205-211.

12. Chelly MR, Major K, Spivak J. The value of laparoscopy in management of abdominal trauma. Am Surg 2003; 69:957-60.

13. Zantut LF, Ivatury RR, Smith RS, et al. Diagnostic and therapeutic laparoscopy for penetrating abdominal trauma: a multicenter experience. J Trauma 1997; 42: 825-831.

14. Chol YB, Lim KS. Therapeutic laparoscopy for abdominal trauma. Surg Endosc. 2003; 17:421-7.

15. Renz BM, Feliciano DV. The length of hospital stay after an unnecessary laparotomy for trauma: a prospective study. J Trauma 1996; 40: 187-190.

16. Gorecki PJ, Cottam D, Angus LD. Diagnostic and therapeutic laparoscopy for trauma: a technique of safe and systematic exploration. Surg Laparosc Endosc Percutan Tech. 2002; 12:195-8. 